\title{
Technological Presence: Actuality and Potentiality in Subject Constitution
}

\author{
Asle H. Kiran
}

Published online: 17 January 2012

(C) The Author(s) 2012. This article is published with open access at Springerlink.com

\begin{abstract}
Technical mediation shapes our experience of the world, but it also shapes our experience of ourselves. In this paper, I argue that in order to understand the latter aspect of technical mediation, we need to expand on notions of technical mediation that focuses on actual use, and bring in possible use as well. The concept of technical mediation must therefore be grounded in a more general concept of technological presence. This concept indicates that technology harbours both actuality and potentiality, the latter denoting that technologies offer possible actions, through which we realise specific actions, and, more importantly, realise ourselves; it is through the technological presence in our lifeworld we are able to recognise our own possibilities to be in and act in the lifeworld. The technologically revealed possibilities enable the subject to be constituted in a temporal forwarddirectedness, so that technological potentiality becomes co-constitutive of the subjects that we are and may become.
\end{abstract}

Keywords Technology $\cdot$ Technical mediation · Lifeworld · Subjectivity · Heidegger $\cdot$ Becoming

\section{Introduction: Technological Presence}

It hardly seems necessary to argue that technology is a pivotal factor in social and scientific development. Think of how the world has changed only since the emergence of the World Wide Web some 20 years ago. The falling circulation of printed newspapers, the new ways in which we relate to friends and colleagues, and how we now access and digest information all testify to the tremendous importance

\footnotetext{
A. H. Kiran $(\bowtie)$

Department of Philosophy, Faculty of Behavioural Science, University of Twente, P.O. Box 217, 7500 AE Enschede, The Netherlands e-mail: a.h.kiran@utwente.nl
} 
information and communication technologies (ICTs) are gaining in our society. Ever cheaper computers and mobile telephones signify that the so-called ICTrevolution is about to go global. In fact, as historian of technology Edward Tenner points out, the very concept of technology "appears to have become a synonym for electronic systems" (2004: ix). However, the social repercussions from older technical breakthroughs such as stone tools, the alphabet, the printing press, and the car go to show that technological impact on the world is nothing recent: with all new human-technology relations comes new human-world and human-human relations. This makes understanding technology important for understanding the structures that make up our lifeworld.

The concept of mediation is helpful in relating technology to the lifeworld. Consider the following examples of technically mediated actions: Using a pen to write a letter, or a mobile phone to send a SMS; using shoes to walk on pebbles or walk barefoot on hot asphalt; using a shovel to dig a hole; using a particle accelerator to discern the tiniest building blocks of the universe. In all of these actions we stand in a relation to the world around us, but this relation is affected, and sometimes profoundly, by the characteristics of the technologies that mediate this relation. We can confirm, or refute the existence of the Higgs boson; we can inform our friend that we will be delayed because of a flat tire; we can enjoy the specific sensation of warm asphalt, etc. because of the specific characteristics of the mediation. Being in a mediated relation to the world means being-in the world in a specific manner; we apprehend the world differently, we experience it differently. Technical mediation, then, causes different experiences of and perspectives on the world in which we are entrenched. In this sense, tools and technologies have consequences for our existence that transcend their particular use.

An influential analysis of the various ways in which technologies mediate our relation to the world is found in the postphenomenological analysis of Don Ihde (1979, 1990). However, Ihde's typology for most part focuses on technologies in-use. That is, it investigates the characteristics of the relation we stand to the world when we interact directly with this or that technology. Other approaches to technical mediation, such as Peter-Paul Verbeek's, have the same focus: "[technical] mediation occurs on the basis of practical dealings with things. When things are used, people take up a relation to the world that these things, thanks to their 'handiness,' coshape" (2005: 211).

Obviously, investigating the effects of technologies in-use is essential in order to understand how technologies contribute to the shaping of the lifeworld. However, focusing on technologies' actuality (that is, in-use) does not amount to a comprehensive account of their significance as lifeworld phenomena. My claim is that rather than focusing on artefacts in-use, technologies' impact should be investigated through the concept of technological presence. This concept expresses that besides the palpable sense in which technologies influence the lifeworld through their actuality, they also influence it through their potentiality. An "idle" piece of technology have several possible roles in technical mediations. Each such role, in its state of possibility, can be called a virtual action. A mobile phone resting in your pocket is virtual communication; it can be utilised to realise the action of talking to a friend-talking to this friend is actualised communication. However, 
while being idle in the pocket, it is also a virtual camera; it can be utilised for taking photographs - it can realise this specific virtual action instead. Many technologies harbour several virtual actions, many of which are surprising side effects to what they were designed to do. ${ }^{1}$ Technologies thus have possibilities that transcend a specific current use, and as such, the technological impact on our lifeworld happens already in presenting us with potentiality, not just through the actual acts. Said differently, technological shaping of the lifeworld happens in terms of possible technical mediations, not just actual technical mediations.

In this article, I explore the implications of shifting the focus from actual technical mediation to the potentiality harboured in the technological presence of our lifeworld. Of particular interest is how this move enables us to grasp how technologies contribute to the shaping, or constitution of subjects. In opening us up to a number of possible actions (the hammer as paperweight, planes as terrorist missiles, mobile phone as guitar ${ }^{2}$ ), technologies' potentiality reflects on how we conduct ourselves, and how we see ourselves as being able to act. We become the kind of subjects that we are through throwing ourselves into projects. The projects we regard ourselves to be able to undertake, to throw us into, is very much related to the technological possibilities we recognise in our lifeworld. Therefore, it is the potentiality and not the actuality of technologies that points us to future actions. And furthermore, in understanding the future through the possibilities offered by technologies, we come to understand our own possibilities as well. Understanding our possibilities means understanding ourselves.

Exploring the latter aspect of technological presence, I go beyond what, in my opinion, has become an unfortunate side to postphenomenology. Ihde has gone to some length to distance himself from the kind of phenomenology that spawned some of the central perspectives and ideas of his own postphenomenological perspective. On my view, though, postphenomenological analysis of technology will gain from keeping close to the analysis of concerned being that is offered by Heidegger.

However, rather than rehashing the famous tool-analysis from Being and Time or Heidegger's later negative view on modern technology I shall discuss Heidegger's concept of being-alongside; one of Dasein's three existential modes of being-in-theworld. This aspect of being-in is not usually discussed in postphenomenological (or other philosophy of technology) contexts, but in order to grasp technology's constitutional role for the subject, it proves informative and valuable. For Heidegger, being-alongside is the relation we have to the world; we, in a state of concern, are alongside worldly entities in their readiness-to-hand (Heidegger 1962: 80f/54, cf. 89/62). ${ }^{3}$ In Edgar Boedeker jr.'s terminology, being-alongside involves an existential perspective on (not in the sense of looking at) the world of entities (2001: 68ff). This perspective is delimited by an existential horizon, and it is

\footnotetext{
${ }^{1}$ Some virtual actions remain unrealised, perhaps for ethical or legal reasons, or perhaps they are never discovered as possible uses of a piece of technology.

${ }^{2}$ http://reviews.cnet.com/8301-19512_7-10283459-233.html [19.09.2011].

3 Dasein ("being there") is Heidegger's subject as always already embedded within, or thrown into, the world. The other two existential modes of being are: being-with (where we are with other Daseins) and, which I won't be discussing, being-one's-self (where we are with ourselves).
} 
"between" (not in a spatial sense) this horizon and wherever we, in our thrownness, are that we can find potentiality. That is, the horizon defines a sort of "space" between where we find ourselves now and to where we might proceed. Note though, that the horizon itself is constituted by the entities that "fill up" this space, and grasping the horizon is only possible in relation to those entities that "fill up" the space. That is, to move towards the horizon (although we can never reach it) involves realising the potential that is found in the entities that we find ourselves alongside. In being presented with an array of possible uses and virtual actions, we come to understand our own potential, as enabled and constrained by the existential horizon. We are constituted as subjects through how we see our own potential; not (just) in relation to what we actually do or have done, but in terms of what we can do, both in a here-and-now perspective and, more existentially, with our lives.

In this article, I shall first establish why the concept of technological presence better captures the technological impact on the lifeworld than the more restricted concept of technical mediation. This involves shifting the focus from actual technical mediations to possible technical mediations, from actuality to potentiality, which I do with help of a concept of "taken-for-grantedness" and Pierre Levy's concept of virtual actions. Having done so, it is possible to explicate the importance of technology on the constitution of the subject.

\section{Ihde's Typology of Human-Technology Relations}

Ihde's typology for how technologies mediate the relation between humans and the world accentuates the fundamental characteristic of technological presence; namely, how our intentionality is shaped by the specific characteristics of artefacts. ${ }^{4}$ Being intentionally directed at the world through a technology transforms our intentional experience in accordance with the characteristics of the artefact. Not even for such tools as a pair of spectacles are there no true transparency in technical mediation; any piece of technology that augments and strengthens our experience of the world will simultaneously reduce or weaken other aspect of it (Ihde 1979: 9). Had the directedness been performed unmediated, or mediated with a different technology, the experience of the world would have been different. Scratching the surface of a blackboard with a dentist's probe produces a tactile experience of the blackboard, but is quite different from the one we would have if we had touched it with our finger directly. Through the probe, we can feel scratches and marks in the surface that we cannot feel with the bare finger. The finger, on the other hand, would have given us experiences of a certain temperature and of the old chalk dust that usually

\footnotetext{
4 Ihde's typology is an implicit criticism of Heidegger's (1977) thesis that modern technologies bring forth one unvarying characteristic, or essence, namely Gestell. For more definite criticism of the analytic one-dimensionality this view implies, see Ihde (2010). Despite discussing technology, and Heidegger, I shall not go into (the later) Heidegger's thoughts on technology. Suffice it to say, I agree with the criticism of the view, which Andrew Feenberg (1999) has dubbed substantivism, of technology as representing one single, unidirectional force that was common in early to mid twentieth century thinking about technology.
} 
covers the surface of blackboards, while the small irregularities would be overlooked (Ihde 1979: 8f). Our experience of the black-board-and our abilities to experience-is therefore augmented in some aspects, while weakened in others. Ihde calls this a 'magnification-reduction structure' (Ihde 1990: 76). ${ }^{5}$ Through a technology the world appears differently, as clearer, more detailed, frailer (with a sledgehammer in hand, a small rock has the hardness of a pile of dirt), etc. At the same time, it appears to be less detailed in other aspects, or out of sight (things that are close and to the side disappears when we look at a distant phenomenon through binoculars), and so on.

According to Ihde, there are three different types of relation we can have to technologies in-use; embodiment, hermeneutic, and alterity. He also considers technologies that are not being used through what he calls the background relations, but, as we shall see, this type fails to grasp the specific type of presence technologies can have in their state of non-use.

An embodiment relation to technology is characterised by a quasi-transparency. In this relation, we deal with technology, but the 'terminus' of our intentional directedness is beyond it; the technologies become " "means' of experience" (Ihde 1979: 8; cf. 1990: 73). Although the directedness of the embodiment relation is quasi-transparent, it nonetheless brings out the specific properties of the involved technologies. Take the example of a hearing aid and the telephone: whereas a hearing aid amplifies all nearby sounds (within certain frequencies), the telephone connects us to a person located distantly (next-door, or in Australia). The telephone, of course, does not pass on all the sounds that exist between us, as if we had giant ears that enable us to hear our conversation partner. For this reason, the telephone does not extend our ears, or hearing, like the hearing aid; it brings the other person nearer to us. ${ }^{6}$ Experientially, embodied technologies do not so much transform our abilities as they transform the appearance of the world. This transformation is the magnification-reduction of the world; it accentuates aspects of the world that are relevant given the kind of mediated technology, how it is interacted with, and in what connection, and play down aspects less important for the technological task.

Moving from an embodiment relation to a hermeneutic relation, means moving from "experiencing through machines to experiences of machines" (Ihde 1979: 11, my emphasis). For instance, cranking up the thermostat to heat a room, the terminus of my intention is the technology itself, the thermostat. The scientific knowledge of sub-atomic particles generated at CERN, is a result of the reading and interpretation of events that are traced, plotted and charted by computers, and it is the heavy technologies that generate the circumstances that are necessary in order to measure particle collisions. We have no perceptual access to the level of particle collisions, but we can control them and perceive them by way of technical mediation. Here, the technology is still a means for world change (warming a room, crashing protons), but the use of it is less transparent than in the embodiment

\footnotetext{
5 In 1979, Ihde used the less agreeable phrase sensory-extension-reduction.

6 More precisely, the telephone brings the other person's mouth nearer to us since we still would be unable to see facial expressions, arm gestures etc.
} 
relation; we are very much aware of the thermostat or the particle accelerator. Intentionally, the world and the technology are apprehended as a unity; we manipulate the world through manipulating the technology.

In the case of alterity relations, we do not treat the technology as pointing beyond itself. $^{7}$ While embodiment and hermeneutic relations denote technical mediations undertaken with the intention of making a real world change, the alterity relation lacks this dimension. However, that is not to say that there are no real world consequences of such an interaction. For instance, buying a soda from a vending machine is an interaction with a machine that does not represent or refer to anything beyond itself (although specific buttons or codes will represent specific sodas). Neither is the interaction perceptually transparent as in the embodiment relation (although steps of it might be, such as inserting coins while locating the code for the soda of choice). All the same, the transaction has an evident real world consequence; if all goes well, you will have an ice-cold soda in your hand within seconds. An alterity relation is defined by us relating to the technology as if it was an other; what Ihde call a quasi-other (embodiment relations indicates that the technology is a quasi-me) (1990: 98).

Some technologies affect our technical mediations, but without us interacting with them. There is no intentional directedness towards the technological items themselves, or, according to Ihde, of the world through them. Our relation to such technologies is of a background type. These technologies shape the context for other experiences. Typical examples are automatic (and semi-automatic) machines and devices. For instance, the earlier mentioned thermostat, once calibrated and programmed will keep the temperature in the room constant. The 'daily' workings of the thermostat do not bother us, only when we need to set a different temperature does it enter our intentional directedness. Semi-automatic appliances, such as washing machines (soaking, soaping, rinsing, centrifuging), and coffeemakers (heating water, moving water, mixing water and coffee), we only interact with at the start or the end of their processes. What is typical of the hidden stages of these technological processes is that they do not display any degree or kind of transparency. Instead, Ihde says, their functioning is characterised by an absence (Ihde 1990: 109).

Intentional absence also characterises clothes, houses and other shelter technologies that first might seem to imply embodiment relations. For these technologies, the same thing holds as above, for instance, bar the odd maintenance, a house does its function, to keep us sheltered from bad weather and prying neighbours, in the background. Clothes and houses are not transparent, they are absent; they are there, but not in an intentional sense. They contextualise our existence, but not as acting in technical mediations. Background relations indicate the manner in which our lifeworld is permeated by technology also in cases we are not aware of it as technologically textured.

As we see, Ihde's typology mainly emphasises the impact actual use of technologies has on the world. This, however, is not exhaustive of the technological

\footnotetext{
7 Ihde (1979) regards alterity relations as a kind of hermeneutic relation. However, I follow Ihde (1990) where these are distinguished as two different kinds of relations.
} 
influence on the relation between the world and us. Technologies that are not in actual use - either as being invisible or as merely being idle-is taken for granted when we organise our daily lives; they are intentionally present in their potentiality. As such, technologies both in their actual use and in their possible use constitute the technological presence in our lifeworld. Let's explore this aspect further.

\section{Taken-for-Grantedness}

Ihde sees background relations as concerning technologies that we never or rarely interact with, and whose function and functioning we take for granted. He delegates such technologies, in a nod to Husserl (1982), to the horizon of technology: "Horizons belong to the boundaries of the experienced environmental field. Like the 'edges' of the visual field, they situate what is explicitly present, while as phenomenon itself, horizons recede" (1990: 114, my emphasis). Apparently, Ihde does not put much emphasis in this notion, primarily discussing it in relation to such phenomena as the anxiety children might experience due to the existence of nuclear weapons. It is my opinion that the concept of horizon is interesting and important in understanding our relation to technology. However, I believe that rather than being a mere background and receding phenomenon, the horizon of technology has a much more active role in shaping the structure of the lifeworld than Ihde assigns it. To grasp this aspect to the notion, however, we need to highlight the specific presence "background" technologies can have even when they, as artefacts, remain in the background. To do this, I shall analyse what is implied in taking certain technologies for granted. This will display how presence is not just an aspect of technologies that goes into technical mediations, but is also the case for technologies Ihde claimed were characterised by their absence. ${ }^{8}$

As we saw, being taken for granted implies that technologies that are not being used remain on the fringe of our current activities. A taken-for-granted status is of course made visible once a piece of technology breaks down. For instance, when the thermostat or the refrigerator are broken we notice (the lack of) their background activity when the living room becomes colder, or the milk has turned sour. In our daily activities, we depend on such functionalities to be working properly. A car driver takes roads and tunnels for granted and may never ever think of them as being part of his technologically structured lifeworld. A mobile user presupposes a sufficiently strong service area. These days, with increasingly better mobile networks, the sheer possibility of online access is taken for granted; internet access will soon be as taken for granted as roads are today. Background technologies profoundly influence the social environment we move around in; they shape the way we live in or perceive our own lifeworld. To put it differently: we organise many parts of our lives in accordance with the background technologies even if they are not taken up and used directly. The way we relate to the world, the way it is

\footnotetext{
${ }^{8}$ Ihde does recognise that also technologies that go into background relations "transform the gestalts of human experience" (1990: 112), but, in not emphasising taken-for-grantedness, does not elaborate whether it might imply a different understanding of technological presence (and absence).
} 
intentionally present to us, is influenced not just by the technology we have "in hand", but also by background technologies. In my opinion, it is therefore wrong to label the "background influence" as an intentional absence.

Also technologies that go into the ordinary technology relations but whose mediating function is not actualised can be seen to harbour a similar aspect. For instance, the ready availability of the telephone might seem to be, at most, a background relation although the actual use is not. However, knowing that we can call, or be called upon, is also an aspect to how we organise our lives. The availability is presupposed in the very act of wanting to realise a specific goal in using them. In a sense, many of the aims and goals we set us are only revealed to us as possible goals by the very technologies we use to realise them. ${ }^{9}$ Such technologies, when "dormant," have a potential actuality that plays directly into how we deal with them, and the world through them.

Taken-for-grantedness implies, then, that there is a technological presence (not quite activity) also when technological items are "idle" and "invisible". Technologies have presence both as actual technical mediations and as potential technical mediations. The concept of technological presence draws attention to the contribution from technologies to the structuring of the lifeworld. We might not actively use this structure, but we always depend indirectly on it in our existence. Background and horizontal technologies should for this reason not be characterised by an intentional absence, but have very much an intentional presence; even when they are not presently in use, they shape how we see and understand our lifeworld. The concept of technological presence, therefore, is important for understanding how we organise our everyday lifeworld existence, not just for how we perform it.

\section{Virtual Actions}

Having expanded on the notion of technical mediation and pointed out the importance of the concept of technological presence for how we "have" a lifeworld, I now want to draw up some further implications of this. As we saw in above, technical mediations, actual and potential, shape the appearance of the world; its structure and how it is experienced. However, another interesting side to technological presence is how it, especially, as we shall see, in terms of its potentialities, opens us up to possibilities that reflects back to us and reveals what we as subjects might become. Technological presence not only mediates our relation to the world, but in so doing, also our self-consciousness. The potentiality found in technology shapes what we regard as our possibilities in the world; enabling and constituting our being in showing us what we might achieve, either right here, right now, or in a lifetime perspective. However, the concept of technological potentiality is still rather too vague to explicate its relevance for the constitution of selves, so in this section I shall discern relation between technological actuality and potentiality.

\footnotetext{
9 This might sound awfully technological determinist. I cannot contextualise this analysis with a full nondeterminist framework, but the next two sections go some distance in refuting that implication. Also, see conclusion.
} 
In the literature on technology, there have been attempts to understand technologies as extensions of our body or mind, or as extensions of our functional bodily make-up. For instance, the hammer might be seen as an extension of our arm, binoculars extensions of our eyes, and so on. However, 'extension' might suit some tools and technologies that are operated by our bodies, but modern technology is much more than that, and it is not hard to find examples that does not sit as easily with this idea as the hammer. The bicycle might fit our conception of an extension of our feet, as might the car, although to a lesser degree, but what about the plane? Moreover, what about the assembly line, the computer? Many technologies are quite remote from the workings of individual or collective bodies. ${ }^{10}$ Rather than regarding, awkwardly, the wheel as an extension of the feet, French media philosopher Pierre Lévy proposes to regard the bicycle as a virtualisation of moving around (1998: 95). In this sense, the hammer, although being operated as an extension of my arm, is better regarded as a virtualisation of the action of hitting. Instead of asking whether MSN is an extension of our mouth in talking, or of our arm in writing, we should regard it as a virtualisation of communicating, as one of several possible ways of actualising this kind of action. According to Lévy, we approach technologies as enabling us to do certain actions, rather than as enabling our body to become stronger, longer, more powerful, etc.

In ordinary usage, the concept of "the virtual" tends towards the hypothetical or that which does not exist in a hands-on material sense, and these days, very much linked to cyberspace. For Lévy, however, the virtual should be taken to be an aspect to everything that exists. Taking his cue from scholastic philosophy, Lévy defines the virtual as that which has potential actuality: "virtuality and actuality are merely two different ways of being" (Lévy 1998: 23). The virtual is always present as the potential inherent in any actuality. "[T]he virtual is a kind of problematic complex, the knot of tendencies or forces that accompanies a situation, event, object, or entity" (Lévy 1998: 24).

It is important to note that an object's potentiality does not refer to only one virtuality; most material objects offers several possible courses of action. The virtual encompasses not only functions defined by a designer, or an item's role in a specific social practice, but also unconventional uses. For instance, while the hammer is a virtualisation of hammering or pulling nails, it is also a virtualisation of holding down a stack of paper and, rather more dramatic, a virtualisation of killing. Almost any technological item can be employed for many kinds of technical mediations, some designed and some not, but only a few becomes the conventional technical mediation. And conversely, while a single piece of technology can virtualise several actions, ${ }^{11}$ one kind of action can be actualised by several technologies. A city bike indicates one way of actualising movement from point A to $\mathrm{B}$, a mountain bike another, while the car indicates yet another way, and so on.

\footnotetext{
${ }^{10}$ See Kiran and Verbeek (2010) for a criticism of the concept of 'technological extensionism'.

11 Usually a technology, in its conventional use, is employed for only one task. Some technologies, however, are designed to do many things, today's mobile phones and computers, for example. The 'double-headed' hammer is also multifunctional, as it has both hammering and pulling nails as conventional uses.
} 
In bringing forward the sense of presence potentiality has although being presence in a material sense, the concept of virtuality helps us see the actual and the potential as two interdependent aspects to phenomena that are materialised and articulated. 'Virtuality' also emphasises the intimate relation between an actual action and a possible action. However, for potentiality to have an actual impact on the lifeworld, we still need to grasp the sense in which an action goes from its virtual state to become an actual action.

\section{The Dynamical Relation Between Potentiality and Actuality}

The virtual, then, is that which is present, although not in-use. It is present in the sense of being a potential but also, as I shall return to below, in the more radical sense of "proposing" an action. In any actuality, there is an element of virtuality, and vice versa: the virtual and the actual go together. This implies that the virtual is the potentiality of the actual, and if it were not for its potential actuality, it would not be a virtuality of an item. Consequently, the concept of the virtual should not be taken as an expression of arbitrariness. In a piece of technology, there is the potential for several actions (for the hammer: hammering, paperweight), but not just any kind of action. For instance, fine-grained brain surgery is not a virtuality of a hammer; to slap someone in the face is not a virtuality of MSN no matter how many angry "smileys" one writes. 'The virtual' expresses the constraints materiality puts on its own actualisations.

On the other hand, actualities enable and constrain our understanding of an item's virtualities since virtualities are usually only revealed to us by way of an actuality. Said differently, only as far as being actualised can some of the virtualities of a technology be disclosed; it must be a "problem" in its actuality that directs our gaze to its potential. I regard this as a revealing of an item's potentiality. In other words, it is the "problem," and the recognition of this "problem," that carries a potentiality from its virtuality to its actuality. However, it is important to emphasise that virtualities do not just suddenly appear once we relate to an actuality, or that virtualities are something inherent in a material item. An actuality implies that something is out in the open (as, say, a material item or as an articulated plan). As such, it can be scrutinised, tested, negotiated, discussed, accepted at face value, rejected altogether, and so on in intersubjective space. We will find that around an actuality there is a social-cultural-ethical-scientific-etc. interplay that contribute to reveal its potentiality; the possible actions an item can be used for. Some possible actions will be blatant, and present themselves almost automatically, others more hidden, and some will never be touched upon at all.

Potentiality is revealed in a number of ways. For instance, only as an actualised function does a technology enter into a technical mediation. This can be a conventional use, in which case the actualisation is in line with its design or its role in a social practice, which, of course, is the most common way of realising a virtual action. However, the revealing aspect to actualities is seen clearer when we consider surprising uses, when we exploit some material properties of an item not really intended as forming a method of use at all. For instance sitting in front of an open 
refrigerator to cool down on warm summer days, or using a blue pill developed to combat high blood pressure to enhance one's erectile function (which pretty fast became the conventional use of this pill). The roles technologies take on in our world often transcend what they were specifically designed for (or their current conventional use). Using a mobile phone for sending text messages is a virtual action of most mobile phones, but from the design perspective, the intention behind this function was to enable the mobile user to receive short messages from the mobile company about such things as incoming voice mails (Taylor and Vincent 2005: 79). ${ }^{12}$

The revealing of potentiality is also seen in regular socio-technological development. Once a technology or technological function is actualised, what is regarded as its strengths and weaknesses are tinkered with. How could we make the piece of technology better? How could we eliminate those aspects of the item that distract us from its primary function? Tinkering is usually done 'positively,' when we try to make the technology better, such as faster computers, increasing RAM, digital cameras with higher resolution, or 'negatively,' when unwanted side effects or alternative uses are eliminated. The crux here is that the potentiality found in the actualised properties of the technologies opens us up to specific ways of developing these technologies further. Galileo Galilei's first telescope had a magnification of $\times 3$, while his last magnified $\times 32$; having established the value of the first, further development of the subsequent ones was motivated. ${ }^{13}$ Another socio-technological reaction to an actualisation is when we are compelled to limit unhappy side effects of technological developments. Palpable today is global warming. Addressing this problem involves many political, juridical and ethical actions, and of course, new kinds of technologies, developed precisely to counter this unhappy consequence: decontamination units, biofuels, catalytic incinerations, and so on.

One further aspect to revealing is how actualities create needs. As pointed out by Langdon Winner, a technological innovation, usually brought forward as a solution to a problem that itself can be or not be technological, sometimes brings with it new preferences, which in turn brings with it new problems that seek new solutions, etc.: "At a certain stage in the development of technics, the need for physical mobility actually becomes the need to have access to automobiles, airlines, or effective equivalents. Such needs are as basic for that stage of technical capacity as the need for good oxen or a good pair of sandals might have been for an earlier one" (1977: 84). Another, more curious, example he mentions is how the industrial techniques of soap manufacture brought forward "an unprecedented desire for well-scrubbed cleanliness that is now second nature to most of us" (Winner 1977: 84.).

The dynamics between actuality and potentiality, then, displays the technological contribution to the revealing of possible tasks we might perform, possible goals we might set, possible problems we might solve, and possible relations we might enter. This extends the importance of technological presence to the structuring of the

\footnotetext{
${ }^{12}$ Earlier mobile phones, hardly mobile at all, were not virtual text senders or receivers, and of course, today mobile phones come equipped with many virtualities.

13 Of course, as emphasised in the sociology of technology, whether, to what extent, and in what direction technologies are developed depends on social, economic, political and scientific processes.
} 
lifeworld. In the case of "normal" use of technologies, the revealing aspect might not be obvious; the majority of technical mediations being governed by social and ethical conventions (and therefore interpreted as "mere means" to reach socially defined goals), but considering innovative use and unintended effects, this becomes more apparent. $^{14}$

This concludes my exploration of the impact of technological presence on how we perceive the world. The dynamics between actuality—revealing-potentiality, however, enables me to turn to another aspect of technological presence, namely its impact on subjectivity.

\section{Existential Horizons}

Whenever we do something, this is not just enabled because of a history that has shaped us into the subjects that we are now; we also live in a way that has the future built into our present concerns. We are, as selves, directed towards the future, and any kind of planning, whether it is an arrangement for our days of retirement, the summer holiday next year, or going to the store for some milk, are performed because we presuppose that we have certain possibilities to do something with our lives. In other words, how we think about, hope for, and anticipate the future-self is important for how we conduct our present lives. We conduct ourselves now in anticipation of what we see ourselves as being able to do, to achieve, both in terms of actions that we are able to undertake in the immediate future and in terms of what we might achieve "in life".

In this section, with support from an analysis of Heidegger's concept beingalongside, I argue that the abilities and possibilities we see ourselves as having are to a large degree related to the potentiality that is revealed in the actuality of our surroundings. Said differently; our selves' temporal forward-directedness relates in a fundamental manner to our lifeworld's technological presence.

Edgar Boedeker jr. regards Heidegger's notion of being-alongside as an existential horizon, which he defines as "roughly, a set of possibilities in terms of which entities are encountered" (2001: 65, my emphasis). ${ }^{15}$ An existential horizon, in the context of Heidegger, involves a temporal aspect, and as such, it underlines that our directedness towards things, or, in the other two existential perspectives, the

\footnotetext{
14 Add to this the sheer complexity and unpredictability of socio-technological development. Technology today amounts to a huge system where what seemingly is a small change can have huge unforeseeable effects. Population estimates for the year 2000 from the sixties was way off because they did not, and could not, predict the existence of the pill. Likewise, a prediction about the year 2011 from 1980s, although it certainly would have included computers, would not have been able to predict the sociocultural effects of the Internet. Technologies introduce something fundamentally more through being available for us to use.

15 In his reading, Boedeker jr. connects Heidegger's concept of the world to Husserl's concept of horizon, but differentiates them by emphasising that an existential horizon should not be regarded as totality of things, but as a totality of meanings (2001: 72, cf. 103, n 2). Note though, that the concept of horizon (without the 'existential') is used in a similar sense by Heidegger himself (1962: 416/365f.; cf. 1988: 302).
} 
Other and oneself, is not static, but involves future matters. In this sense, the existential horizon is elusive; we can never reach it (there is always a future also in the future), and never transcend it (we cannot go ahead of the future). However, it will always be conspicuously present as the ultimate contextual limit for understanding that which lies before us, between the horizon and us, in a manner of speaking. In our thrownness in-the-world, Heidegger tells us, we belong to three modes of being-in. In Boedeker jr's terms, we are "facing" three existential horizons: in our being-alongside things, the 'world' is the horizon; in our being-with Others, das Man is the horizon; and in our being-one's-self, Death is the horizon. ${ }^{16}$

Equiprimordial to our thrownness in-the-world, Heidegger claims that we project ourselves as our own possibilities in-the-world towards the future-as-horizon. This projection is not a plan we form about how to conduct ourselves; instead, it is a fundamental directedness towards the future; towards the existential horizon. The basic idea is that what we are now is constituted not merely by what has been and what now is the case, but also by what we might become: "to [Dasein's] facticity its potentiality-for-Being belongs essentially. Yet as Being-possible, moreover, Dasein is never anything less; that is to say, it is existentially that which, in its potentialityfor-Being, it is not yet" (1962: 185f/145). In other words, the self is not only what it sees itself as being 'right here, right now', but it also sees itself in terms of its own possibilities. Our possibilities, in turn, are related to the thrownness, in the sense that we can only 'become' in relation to that which we are-alongside and that which we are-with. Consequently, our possibilities are in accordance with the existential horizons of things (the 'world') and the Others (das Man); we project ourselves towards the horizons through co-thrown entities.

This implies no determinism. As Heidegger says himself: "Dasein can understand itself in terms of the 'world' and Others or in terms of its ownmost potentiality-forBeing" (1962: 264/221). For instance, although we can be totally absorbed in das Man's ways of interpreting events and phenomena in our surroundings, we are not condemned to it. For the most part and in our everyday dealings, we depend on the conventions and norms into which we have been socialised, but we have also the possibility to form ourselves. Likewise, I can use a double-headed hammer to hold a window open, although the conventional use is for hammering or pulling. However, this might imply, conversely to determinism, that we have a mere instrumental relation to technologies, but this is not the case either. Although my use of the hammer formally is my interpretation, it is nonetheless related to the potentialiy of the hammer itself; the holding-the-window-open is enabled by the materiality of the hammer; in the terminology of the previous two sections, it is a virtual action of the hammer. We have a freedom towards the thing-world and a freedom towards

\footnotetext{
${ }^{16}$ I shall ignore the last existential horizon, but I will return to das Man. For Heidegger, das Man denotes that we most fundamentally exist 'integrated' with this Other, which for the sake of clarity we can call the social. Dasein only emerges as an 'I' (and simultaneously, the others as Others) out from this 'unity'. Therefore, the ' $\mathrm{I}$ ' is not ontologically prior to the Other, but neither is the Other prior to the 'I'. Of course, physically we are separate entities, but Heidegger's point is that as part of das Man, we act, we speak and we think as if on behalf of a community. The concept of das Man is useful because the characteristics of our being-alongside and the discovery of ourselves are easier to expound in relation to our social existence. In addition, being-alongside and being-with are interrelated in numerous ways.
} 
das Man, but even so, this freedom is still within the existential horizon, it is interdependent on me, my things, and my social belonging.

For Heidegger, what constitutes the 'world' is the totality of equipmental contexts to which things in their readiness-to-hand refer.

In anything ready-to-hand the world is already 'there'. Whenever we encounter anything, the world has already been previously discovered, though not thematically. But it can also be lit up in certain ways of dealing with our environment. The world is that in terms of which the ready-to-hand is readyto-hand (1962: 114/83).

Reading this statement in the terms introduced above, the 'world' becomes the potentiality enabled by things, and it is in terms of its potentiality that the 'world' forms the limits of our possible understanding of the thing-world. Through readiness-to-hand the things that make up the 'world' and the 'world' that the things are within are assigned to each other through their potential practical relations. As such, the 'world' constitutes the existential horizon of our possible actions, and consequently it constitutes how we see our own (practical) possibilities in the world (Heidegger 1962: 120/87, cf. 185/134).

Combining the notion of the future directedness of the existential horizon with the notion of potentiality, 'world' is not understandable merely in terms of the things and conventional uses that are, but also those things and uses that may become actualised. The realisation of these requires that we are not just dependent upon what is, but that we can project ourselves through potentiality as well.

\section{Situated Openness}

As mentioned, in the mode of being-in that Heidegger calls being-with, it is das Man that forms the existential horizon. Although dealings with things have repercussions for Dasein itself (especially in revealing a world), the possibilities we can project ourselves into towards the intersubjective horizon are more directly connected to the realisation of Dasein's everyday conception of itself; how we have grown into roles, into a personality (or personalities), and as maintaining social functions, in short, how we understand ourselves in relation to Others. Around us, in our existential perspective towards the existential horizon of das Man, we can find a wealth of such relations. In a manner similar to how the hammer is nothing in itself-it is a hammer only to the extent that in figures in an equipmental context-any job, any social activity is nothing in itself, it gains its meaning from how it is related to other social roles.

Heidegger regards an existence engrossed in das Man as inauthentic. The main reason for this is it that das Man is oppressive and that we in our everyday dealings willingly conform to the rules and conventions found in the social. But it is also the case that it is through das Man that social behaviours gain their meaning, and this does not necessarily mean in an oppressive form; it does not necessarily imply social conformism. Instead, it can be seen as a more general argument. The teenager rebelling against his parents, the outsider preferring to live as a homeless person 
instead of receiving welfare, the solitary monk - all these roles that are attempts to find one's own identity are meaningful only to the extent that they are related to the opposing (and more conforming) social roles. Being-alone presupposes beingwith. $^{17}$

This entails, then, that in saying that our social possibilities are constituted by the directedness towards the horizon of das Man, we are not condemned to conformity, we do not have to become something that already is. It only means that whatever we become, it will be, or must be, related to what already is. We cannot go outside of and be totally independent of Others. Whatever social role we enter, it will be meaningful only to the extent that it is possible to define it in relation to Others. In Boedeker's words, the existential horizon of das Man, "is the network of possible ways for Daseins to be, it is constituted by possibilities to which Dasein can take others as referring" (2001: 74). With the concept of das Man, Heidegger primarily pays attention to the historical and cultural belonging each and every Dasein is thrown into (1962: 439ff/387ff).

Nonetheless, it is indeed the case that Heidegger sees our everyday dealings with Others as being a determined way of life: "The public deprives Dasein of its choice, its formation of judgments, and its estimation of values; it relieves Dasein of the task, insofar as it lives in the Anyone [das Man], to be itself by way of itself" (1992: 247; cf. 1962: 165/127). This, then, implies that in our everyday roles we conform to the preferences and conventions of das Man, which in turn has implications for how we deal with our surroundings (including how to deal with things and equipment since most use of tools and technologies conforms to social practices). Escaping this state involves stepping out of everydayness. Heidegger thus makes our assuming a non-determined state a considerable effort.

This has repercussions for how to understand our relation the thing-world as well; are we condemned to social practices and conventional uses? In my opinion, the framework that now has been developed show us why this is not the case. Through the potentiality of its materiality, technologies transcend social conventions for use. As we saw above, it is not the case that all of our relating to technologies is mediated through social practices. Using a regular living room chair as a ladder when I hang a picture on my living room wall, is neither a use that is governed by the chair's social role, nor is it an inventive use that was entirely discovered by me. Instead, it is a potential use that is revealed in my interaction with the chair's materiality; being a ladder is a virtual readiness-to-hand of the chair. A brief example, admittedly, but it nevertheless indicates how virtuality prevents us from ending up in the social conformism that threatens Heidegger's conception of das

\footnotetext{
${ }^{17}$ It is important to note that Dasein discovering itself as someone other than the Other does not coincide with Dasein reaching authenticity, because "even in its fullest concretion Dasein can be characterised by inauthenticity —when busy, when excited, when interested, when ready for enjoyment" (Heidegger 1992: 68/43). While Dasein's being-alongside things is characterised by concern, our being-with with other Daseins is characterised by solicitude, a caring for. Solicitude is expressed as a mixture of inauthentic care, called 'leaping-in', which is marked by a mistrust of and domination over each other, and authentic care, called 'leaping-ahead', which is marked by a helpful approach to the liberation of Dasein itself. (1992: 158f/122).
} 
Man and that could have been extended to a social determinism in our handling of technology.

In this way, we can say that it is not the self, nor the social, nor technology that is primordial in the shaping of each other. The primordial is the situatedness in which we find ourselves. Only in the situatedness can we be opened to our possibilities, and only in recognising our own possibilities can we become ourselves.

Dasein has always made some sort of decision as to the way in which it is in each case mine... [Dasein] comports itself towards its Being as its ownmost possibility. In each case Dasein is its possibility, and it 'has' this possibility but not just as a property, as something present-at-hand would. And because Dasein is in each case essentially its own possibility, it can, in its very Being, 'choose' itself and win itself; it can also lose itself and never win itself; or only 'seem' to do so (Heidegger 1992: 68/42).

We find ourselves as thrown into a social and technological world that is structured by (always) already existing structures that we cannot help but relate to, but in our thrownness we can project ourselves into the future-as-horizon with a choice to conform to the already existing structures (I can refuse to use the hammer for anything other than hammering and instead look for something else to keep the window open), or I can find possibilities that transcend those that exist. As I said above, virtualities present us with solution strategies to actualised problems; these virtualities reflect back to us and become our own possibilities.

\section{In Closing}

In discussing technical mediations, we saw that the technologies we use accentuate aspects of the world in accordance with the characteristics of the materiality of the mediating technologies. Synchronously, we ourselves are accentuated in this process; there is never a bare subject facing a bare object in a technical mediation, subject and object are constituted through the mediated relation. A book can be both reading material and flammable, and a boy can be both an avid reader and a pyromaniac with the help of a pair of spectacles. ${ }^{18}$ However, as we saw, this not only holds for actualised mediations, also potential mediations constitute subject and object; potentiality show us how the world could be and how we could be in-the-world. Through this constitutional double-act, we become forward-directed subjects; we project ourselves towards our own future, and find ourselves, our plans and hopes, and our possible accomplishments.

This should not be taken to imply technological determinism. Being influenced, shaped, even constituted by our surroundings, social or technological, is not necessarily (although it can be) oppressive and determining. Only in relating to that we are alongside, or with, can we become something alongside or with. That or those which we are alongside and with mark the horizon of our possibilities, but in so doing, also our constraints. There is no mutual exclusion between possibilities

$\overline{18}$ The interdependent accentuation of subject and object is more thoroughly examined in Kiran (2011). 
and constraints; both aspects require situatedness, both aspects only appear in mediation, and both aspects are only understandable in relation to each other. Technological presence, therefore, offers us opportunities, possibilities, and reveals to us potential actions, potential forms of life, and potential ways of relating to our social and physical surroundings. Technical mediation is a way of realising our own potential by actualising an item's potential.

Acknowledgments This article was made possible by NWO, Netherlands Organization for Scientific Research (Programme: Socially Responsible Innovation, project "Telecare at Home"). The author would like to thank Peter-Paul Verbeek, Aud Sissel Hoel, Robert Scharff, and Finn Olesen for their valuable comments on earlier versions of this article.

Open Access This article is distributed under the terms of the Creative Commons Attribution Noncommercial License which permits any noncommercial use, distribution, and reproduction in any medium, provided the original author(s) and source are credited.

\section{References}

Boedeker, E. C., Jr. (2001). Individual and community in early Heidegger: Situating das man, the man-self, and self-ownership in dasein's ontological structure. Inquiry, 44, 63-99.

Feenberg, A. (1999). Questioning technology. London: Routledge.

Heidegger, M. (1962). Being and time. Oxford: Basil Blackwell.

Heidegger, M. (1977). The question concerning technology. In M. Heidegger (Ed.), The question concerning technology, and other essays (pp. 3-35). New York: Harper \& Row.

Heidegger, M. (1988). The basic problems of phenomenology. Bloomington: Indiana University Press.

Heidegger, M. (1992). History of the concept of time. Bloomington: Indiana University Press.

Husserl, E. (1982). Ideas pertaining to a pure phenomenology and to a phenomenological philosophy. Dordrecht: Kluwer.

Ihde, D. (1979). Technics and praxis. Dordrecht: Reidel.

Ihde, D. (1990). Technology and the lifeworld. From garden to earth. Bloomington: Indiana University Press.

Ihde, D. (2010). Heidegger's technologies: Postphenomenological perspectives. New York: Fordham University Press.

Kiran, A. H. (2011). Responsible design. A conceptual look on interdependent design-use dynamics. Philosophy \& Technology. doi:10.1007/s13347-011-0052-5.

Kiran, A. H., \& Verbeek, P. P. (2010). Trusting our selves to technology. Knowledge, Technology \& Policy, 23, 409-427.

Lévy, P. (1998). Becoming virtual. Reality in the digital age. New York: Plenum Trade.

Taylor, A. S., \& Vincent, J. (2005). A history of SMS. In L. Hamill \& A. Lasen (Eds.), Mobile world: Past, present and future (pp. 75-91). London: Springer.

Tenner, E. (2004). Our own devices. How technology remakes humanity. New York: Vintage Books.

Verbeek, P. P. (2005). What things do philosophical reflections on technology, agency, and design. University Park: Pennsylvania State University Press.

Winner, L. (1977). Autonomous technology. Technics-out-of-control as a theme in political thought. Cambridge, US: MIT Press. 